\title{
A cadaveric study of variations in the branches of popliteal artery in South Indian population
}

\author{
Sumana. $\mathbf{R}^{1, *}$, Shivakumar .A.H ${ }^{2}$ \\ ${ }^{1}$ Professor and HOD, ${ }^{2}$ Professor, Dept. of Anatomy, ${ }^{1}$ Velammal Medical College, Hospital \& Research Institute, (Affiliated to \\ the Tamilnadu Dr MGR Medical University) Madurai, Tamil Nadu, ${ }^{2} \mathrm{JJM}$ Medical College, Davangere, Karnataka, India
}

*Corresponding Author:

Email: sumsdr@rediffmail.com

Received: $16^{\text {th }}$ February, 2018

Accepted: $19^{\text {th }}$ April, 2018

\begin{abstract}
Introduction: Popliteal artery gains much importance because of the clinical conditions encountered and the surgeries carried out in the region of popliteal fossa. The variations in the branching pattern of popliteal artery is observed and studied by many as the knowledge of its variations will be of relavence during the vascular surgeries, fasciocutaneous flaps and surgeries of knee.

Materials and Methods: Present study is conducted on 50 lower limb specimens belonging to the department of Anatomy of Karuna medical college by detailed dissection and tracing of all its branches.

Results and Discussion: Two out of 50 specimens showed the presence of superficial sural artery accompanying the sural nerve very rare but very important one. No variation in the course of the popliteal artery was encountered. Trifurcation of popliteal artery was not encountered in the present study.

Conclusion: The present study shows the importance of the superficial cutaneous branch of the popliteal artery with respect to the fasciocutaneous flaps an important finding for the plastic surgeons \& surgeries where fasciocutaneous free and pedicled flaps can be raised over the superficial cutaneous branches of Popliteal artery.
\end{abstract}

Keywords: Superficial sural artery, Fasciocutaneous flaps, Superficial sural artery flap.

\section{Introduction}

Popliteal artery being one of the important arteries of the lower limb, gains much importance clinically because of the conditions such as entrapment of popliteal artery which happens due to its varied course and surgeries where fasciocutaneous free and pedicled flaps can be raised over the superficial cutaneous branches of popliteal artery.

Popliteal artery is the continuation of femoral artery through $5^{\text {th }}$ osseoaponeurotic opening in the adductor magnus descends down and laterally then vertically downwards upto the lower border of popliteus muscle and terminates by dividing in to anterior and posterior tibial arteries.

Popliteal artery branches can be classified in to terminal branches, muscular branches, cutaneous branches and genicular branches.

The present study is aimed at the variations in the branching pattern of the popliteal artery and also the variations encountered in the course of the branches.

Popliteal artery entrapment can happen when popliteal artery pass medially beneath the medial head of Gastronemius muscle or even beneath an aberrant band of muscle in the popliteal fossa.

\section{Materials and Methods}

The study was carried out to determine the branches of the popliteal artery in the popliteal fossa. 50 limbs were selected for the present study irrespective of the gender. The 50 specimens were collected from 10\% formalin fixed human cadavers during routine undergraduate dissection in the Department of Anatomy, over a period of 8 years by routine procedure of standard dissection of cadavers. Detailed dissection was carried out in the limbs in the region of popliteal fossa and the branches were traced till the end.

\section{Observation}

All the branches of popliteal artery were traced and the observations were noted.

The Superficial cutaneous branch is painted red for the purpose of differentiation and the sural nerve is painted lemon yellow colour.

Out of the 50 limbs selected for the study 2 limbs showed the presence of large superficial cutaneous branch accompanying the sural nerve.

Trifurcation of popliteal artery was not encountered in the present study.

No variation in the course of the popliteal artery was encountered.

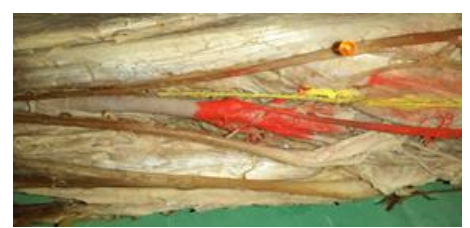

Fig. 1: Origin of the large cutaneous branch from the popliteal artery 


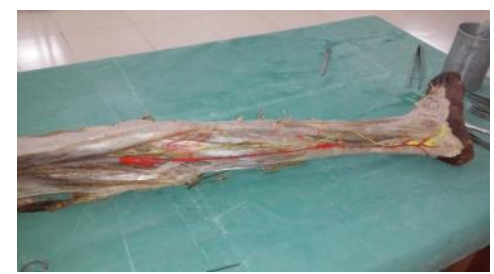

Fig. 2: Entire course of the large cutaneous branch accompanying the sural nerve right leg

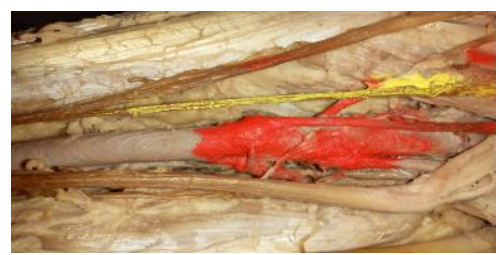

Fig. 3: Photograph showing the branches of popliteal artery at popliteal fossa

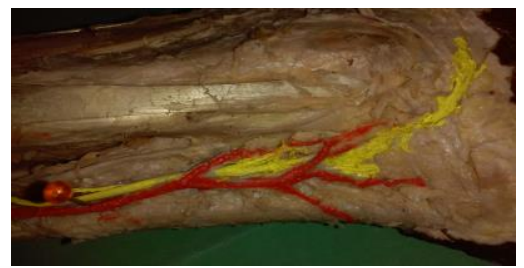

Fig. 4: Photograph showing the termination of the cutaneous branch at ankle

\section{Discussion}

The Cutaneous branches of the popliteal artery otherwise known as the superficial sural arteries (Henry Grey, ${ }^{1}$ ) are usually 3 in number, originate either directly from the popliteal artery or its terminal branches and descend between the two heads of gastronemius muscle then perforate the deep fascia to supply the skin of the back of the leg. The three branches are median, medial and lateral superficial cutaneous arteries out of which the median or the central branch is usually larger and accompanies the sural nerve.

The popliteal artery usually terminates by dividing into its terminal branches namely the anterior tibial artery and Posterior tibial artery and the peroneal artery will be the branch from anteroir tibial artery. In case of trifurcation of the popliteal artery the popliteal artery divides in to anteroir tibial, posterior tibial and peroneal arteries.

In the present study we encountered a large superficial cutaneous branch originating from the popliteal artery in the popliteal fossa and accompanying the sural nerve throughout its course.

There was no variation in the course of popliteal artery or the entrapment of popliteal artery.

The distally based superficial sural artery flap, firstreported by Masquelet in $1992,{ }^{2}$ is another good alternative and has been used widely for reconstructing soft tissue defect in distal leg and ankle. The distally based superficial sural artery flap referred as "sural flap" has become a major tool for reconstruction of the distal leg, ankle, and foot as described by Haug M D et al $2008^{3}$ and according to the study of Nakajima et al, ${ }^{4}$ the accompanying artery of the sural nerve (the median superficial sural artery) had few perforators to the skin in the upper half of the leg. Most recent study by Ali Mojallal et al in Feb $2017^{5}$ on the accompanying arteries of the sural nerve and the lesser saphenous vein were studied. In 73 percent of all dissections, only one artery was associated with both the sural nerve and the lesser saphenous vein. Two accompanying arteries were observed in 27 percent of the cases, correlates well with the present study where 2 of 50 specimens shows artery accompanying sural nerve.

\section{Conclusion}

Variation of the popliteal artery is the trifurcation, where all the three terminal branches arise together at the level of the lower boundary of the popliteus muscle. Trifurcation of the popliteal artery into anterior tibial, posterior tibial and peroneal branches was observed in $4.3 \%$ in Keen's study, ${ }^{6}$ but it is not observed in the present study.

Owing to the variations observed in the branches and the course of the branches of the popliteal artery the surgeons are to be extremely careful during the fascio cutaneous free and pedicled flaps that may be raised on superficial sural arteries and during the surgeries of the lower limb.

\section{References}

1. Gray's anatomy: The Anatomical basis of clinical practice. In: Mahadevan V. Knee. 40th ed. Elsevier. Churchill livingstone;2008. p.1393-410.

2. Masquelet AC, Romana MC, Wolf G. Skin Island Flaps supplied by the Vascular Axis of the Sensitive Nerves: Anatomic Study and Clinical Experience in the Leg. Plast Reconstr Surg 1992;89:1115-21.

3. Haug MD, Valderrabano V, Rieger UM, Pierer G, Schaefer DJ.Anatomically and biomechanically based algorithm for foot and ankle soft tissue reconstruction (in German). Handchir Mikrochir Plast Chir. 2008;40:37785.

4. Nakajima H, Imanishi N, Fukuzumi S et al. Accompanying Arteries of the Lesser Saphenous Vein and Sural Nerve: Anatomic Study and its Clinical Applications. Plast Reconstr Surg 1999; 103:104-120.

5. Ali Mojallal, M.D.Corrine Wong, M.R.C.S.Christo Shipkov, M.D.Steven Bailey, M.D.Rod J. Rohrich, M.D.Michel Saint-Cyr, M.D.Spencer A. Brown, Ph.D. Superficial Sural Artery Flap;2017; vol126,no 4; 1240-52.

6. KEEN JA: A study of the arterial variations in the limbs, with special reference to symmetry of vascular patterns. Am J Anat. 1961 May;108:245-61. [PubMed]

7. MORRIS GC, Jr, BEALL AC, Jr, BERRY WB, FESTE J, DE BAKEY ME: Anatomical studies of the distal popliteal artery and its branches. Surg Forum.1960;10:498-502. [PubMed] 
8. Bardsley JL, Staple TW: Variations in branching of the popliteal artery. Radiology.1970 Mar;94(3):581-

7. [PubMed]

9. Sackler JP, Abrams BM, Beranbaum ER: Congenital absence of the anterior tibial artery. Angiology. 1968 Feb;19(2):67-74. [PubMed]

10. Zwass A, Abdelwahab IF: A case report of anomalous branching of the popliteal artery. Angiology. 1986 Feb;37(2):132-5. [PubMed] 